\title{
Oxytocin signaling in basolateral and central amygdala nuclei differentially regulates the acquisition, expression, and extinction of context-conditioned fear in rats
}

\author{
Emma J. Campbell-Smith, Nathan M. Holmes, Nura W. Lingawi, Marios C. Panayi, \\ and R. Frederick Westbrook \\ School of Psychology, University of New South Wales, New South Wales, 2052, Australia
}

\begin{abstract}
The present study investigated how oxytocin (OT) signaling in the central (CeA) and basolateral (BLA) amygdala affects acquisition, expression, and extinction of context-conditioned fear (freezing) in rats. In the first set of experiments, acquisition of fear to a shocked context was impaired by a preconditioning infusion of synthetic OT into the CeA (Experiment 1) or BLA (Experiment 2). In the second set of experiments, expression of context fear was enhanced by a pre- or post-extinction CeA infusion of synthetic OT (Experiments 3-6) or a selective OT receptor agonist, TGOT (Experiment 4). This enhancement of fear was blocked by coadministration of an OT receptor antagonist, OTA (Experiment 5) and context fear was suppressed by administration of the antagonist alone (Experiment 6). In the third set of experiments, expression of context fear was suppressed, not enhanced, by a preextinction BLA infusion of synthetic OT or a selective OT receptor agonist, TGOT (Experiments 7 and 8). This suppression of fear was blocked by coadministration of the OT receptor antagonist, OTA (Experiment 8). Taken together, these findings show that the involvement of the CeA and BLA in expression and extinction of context-conditioned fear is dissociable, and imply a critical role for oxytocin signaling in amygdala-based regulation of aversive learning.
\end{abstract}

\begin{abstract}
The amygdala is an anatomically and functionally heterogeneous structure. Two of its nuclei, the basolateral amygdala (BLA) and central amygdala (CeA), play dissociable roles in fear conditioning in rats (Sah et al. 2008; Pape and Pare 2010; Lee et al. 2013). The BLA is a site of convergence for sensory inputs conveying information about danger and its stimulus antecedents. This convergence leads to associative formation, instantiated via a series of extra- and intracellular processes that lead to changes in synaptic efficiency (e.g., long-term potentiation of monosynaptic thalamic inputs). In this manner, stimuli predictive of danger activate intrinsic pathways from BLA to CeA. Once activated, neurons in the CeA coordinate various components of defensive or fear responses (e.g., autonomic, endocrine, behavioral) via their projections to distinct midbrain structures (e.g., hypothalamus, brainstem, and periaqueductal gray; LeDoux 2007; see also Ciocchi et al. 2010; Haubensak et al. 2010).

Several studies have shown that fear conditioning is regulated by $\gamma$-aminobutyric acid (GABA) transmission in BLA and CeA. Infusion of the $\mathrm{GABA}_{\mathrm{A}}$ agonist, muscimol, into either region impairs acquisition and expression of fear responses to both discrete (Muller et al. 1997; Wilensky et al. 2006) and context-conditioned stimuli (Huff et al. 2005). Other evidence suggests that GABA transmission in the amygdala is regulated by the neuropeptide, oxytocin (OT). An infusion of OT into the CeA increases GABA activity in this region (Huber et al. 2005). Furthermore, increases in CeA OT reduce expression of fear: conditioned freezing is suppressed following infusion of a selective OT agonist (Viviani
\end{abstract}

Corresponding author: f.westbrook@unsw.edu.au Article is online at http://www.learnmem.org/cgi/doi/10.1101/Im.036962.114. et al. 2011) or optogenetic stimulation of hypothalamic neurons, which has the effect of increasing CeA OT (Knobloch et al. 2012).

Increases in central OT signaling do not uniformly reduce expression of conditioned fear: conditioned freezing is increased, not suppressed, following intracerebroventricular (i.c.v.) OT administration (Toth et al. 2012). The contrasting effects of central OT infusion on context-conditioned freezing may relate to the fact, when administered i.c.v., OT either does not act on oxytocin receptors in the CeA, or that the effect of OT on the CeA is offset by its effects on other brain regions, e.g., the BLA (Kremarik et al. 1993; Huber et al. 2005; Terenzi and Ingram 2005).

At present, the selective effects of OT administered into the CeA or BLA on acquisition of context-conditioned fear are not clear (see Lahoud and Maroun 2013). It is also unknown how OT administered into either the CeA or BLA affects the inhibition of fear responses that usually occurs during exposure to the context alone (i.e., in the absence of shock): that is, across extinction of conditioned fear responses. Accordingly, the present study had three aims: First, to examine the effect of a CeA or BLA OT infusion on acquisition of conditioned fear in rats; second, to examine the effect of a CeA or BLA OT infusion on expression and extinction of conditioned fear; third, to determine the receptor-specificity of any observed differences.

(C) 2015 Campbell-Smith et al. This article is distributed exclusively by Cold Spring Harbor Laboratory Press for the first 12 months after the full-issue publication date (see http://learnmem.cshlp.org/site/misc/terms.xhtml). After 12 months, it is available under a Creative Commons License (AttributionNonCommercial 4.0 International), as described at http://creativecommons. org/licenses/by-nc/4.0/. 


\section{Results}

\section{The effect of OT infused into CeA or BLA on acquisition of context-conditioned fear}

\section{Experiment 1: $\mathrm{CeA}$ infusion of OT impairs acquisition of context-conditioned fear}

A recent study reported that acquisition of context-conditioned fear was spared by a presession infusion of synthetic OT into the CeA, but impaired by a presession CeA infusion of a selective OT receptor (OTr) agonist, WAY-267474 or TGOT (Lahoud and Maroun 2013). The absence of a synthetic OT effect may have been due to the very low concentration of synthetic OT used in the study ( $6 \mathrm{ng} / 0.3 \mu \mathrm{L})$. Accordingly, this present experiment examined the effect of a CeA infusion of synthetic OT on acquisition of context-conditioned fear using a much larger dose of the drug relative to that used previously $(75 \mathrm{ng} / 0.3 \mu \mathrm{L})$. This concentration was selected based on pilot studies conducted in the laboratory. Rats were implanted with bilateral cannulae targeting the CeA. Rats received a CeA infusion of saline (Group SAL) or OT (Group OT) $10 \mathrm{~min}$ prior to context-shock pairings (two shocks) on Day 1, and were tested for fear of the context on Day 2 (Fig. 2A; Table 1). Figure 1 (left) shows the location of CeA cannula tips for rats in Experiment 1 and Experiments 3-6. The plotted points represent the ventral point of the cannula track.

Freezing increased linearly across the conditioning session, $F_{(1,17)}=73.32 ; P<0.05$. The main effect of group and the group $\times$ trend interaction were not significant, larger $F_{(1,17)}=2.73 ; P>$ 0.05 , showing that there was no significant difference in the rate at which freezing increased in Groups SAL and OT, and averaged across all trials, no overall difference in freezing between Groups SAL and OT.

Figure $2 \mathrm{~B}$ (right) shows the levels of freezing to the context across the test session on Day 2. All rats exhibited substantial levels of freezing when reexposed to the context, however these levels significantly decreased across the test session, $F_{(1,17)}=$ 30.43; $P<0.05$, indicating extinction of context-conditioned fear. The trend $\times$ group interaction was not significant, $F \mathrm{~s}_{(1,17)}<$ $1.20 ; P>0.05$, but there was a significant main effect of group,

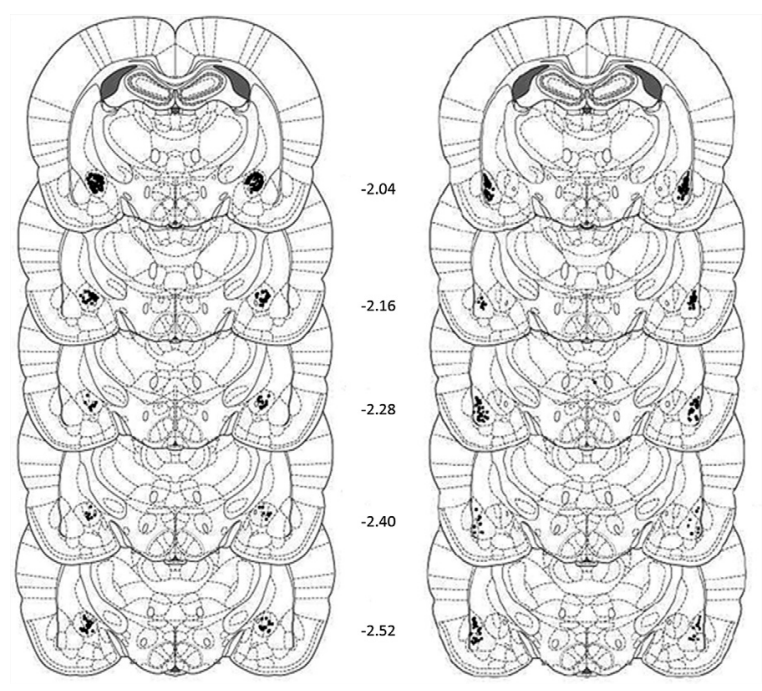

Figure 1. Cannula placements for the 145 subjects in experiments targeting the $\mathrm{CeA}$ (left) and 124 subjects in experiments targeting the BLA (right). The filled circles represent the location of the cannula tips at five different rostral-caudal planes. The numbers represent the posterior coordinates (millimeters) from bregma.
$F_{(1,17)}=5.88 ; P<0.05$, showing that rats infused with OT before the conditioning session froze significantly less on test than rats infused with saline.

In summary, while there were no differences in freezing levels across the conditioning session, rats that received a CeA OT infusion before conditioning froze significantly less at test, implying weaker encoding of the context-shock association.

\section{Experiment 2: BLA infusion of OT impairs acquisition of context-conditioned fear}

OT receptors are densely distributed in the lateral region of the CeA. As such, this nucleus has been the focus of most research examining the role of amygdala OT signaling on acquisition or expression of context-conditioned fear. However, OT receptors are also present in the most rostral extent of the BLA, and increases in OT signaling in this region (via direct infusion of synthetic OT or selective OTr agonists) have been shown to enhance acquisition of context-conditioned fear (Lahoud and Maroun 2013). The present experiment constituted a further examination of the effect of BLA OT signaling on acquisition of context-conditioned fear. It used the same protocol and parameters as Experiment 1 . Rats were implanted with bilateral cannulae targeting the BLA. All rats received an intra-BLA infusion of either saline (Group SAL) or OT (Group OT) 10 min prior to context-shock pairings (two shocks) on Day 1, and were then tested under extinction conditions for acquisition of context-conditioned fear on Day 2 (Fig. 2A). Figure 1 (right) shows the location of BLA cannula tips for rats in Experiment 2 and Experiments 7-8. The plotted points represent the ventral point of the cannula track.

All rats froze after the shock on Day 1. Levels of freezing increased linearly across the conditioning session, $F_{(1,16)}=34.04$; $P<0.05$. The trend $\times$ group interaction was not significant, $F_{(1,16)}<4.20 ; P>0.05$, and there was no significant difference in freezing between Groups SAL or OT, $F<1$.

Figure 2C (right) shows the levels of freezing to the context across test on Day 2. All rats exhibited substantial levels of freezing when reexposed to the context. Levels of freezing significantly decreased across the test session, demonstrating extinction, $F_{(1,16)}=$ 41.35; $P<0.05$. The main effect of group, $F_{(1,16)}=9.16 ; P<0.05$, and the trend $\times$ group interaction, $F_{(1,16)}=9.18 ; P<0.05$, were both significant, demonstrating that Group OT showed lower overall levels of freezing and extinguished faster than Group SAL.

In summary, the pattern of results in this experiment was identical to that obtained in Experiment 1. There were no differences in freezing levels across the conditioning session; however, rats that received a BLA infusion of OT before conditioning froze significantly less at test, implying weaker encoding of the context-shock association.

\section{The effect of an OTr agonist or antagonist on short- and long-term inhibition of fear responses when infused into the $\mathrm{CeA}$}

\section{Experiment 3: $\mathrm{CeA}$ infusion of OT impairs short- and long-term inhibition of fear responses}

Previous studies have shown that a CeA infusion of a selective OT agonist (TGOT) or increases in OT via optogenetic stimulation of hypothalamic neurons decreased fear responses across the extinction session (Viviani et al. 2011; Knobloch et al. 2012). However, these studies did not assess the effects of the drug on the longterm inhibition of fear responses produced by that extinction session. In the present experiment, all rats were implanted with bilateral cannulae targeting the CeA. Rats were shocked in the context on Days 1 and 3, reexposed to the context under extinction on 

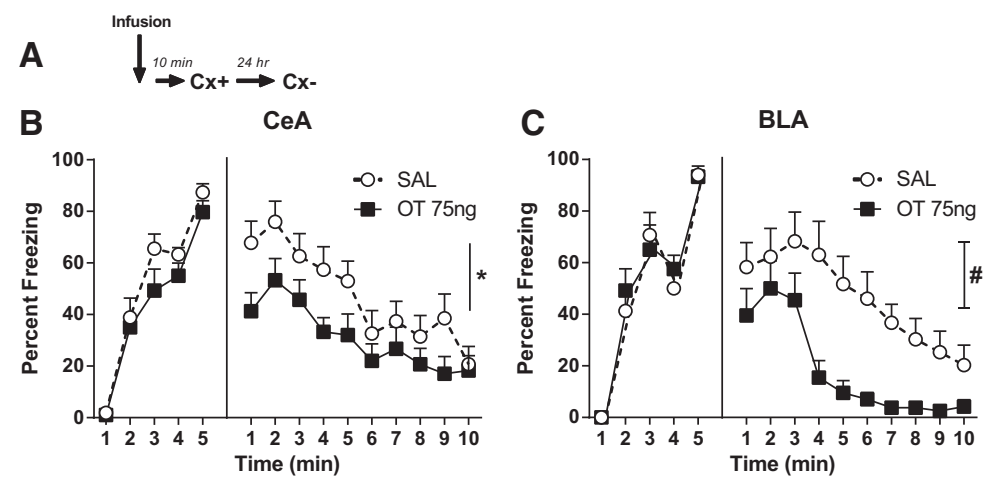

Figure 2. The effects of intra-amygdala infusions of OT on acquisition of context-conditioned fear. $(A)$ Timeline of the experimental procedure; $C x+$ and $C x$ - represent context-shock and context extinction sessions, respectively. (B) Mean ( + SEM) percent freezing to the context across the acquisition (left) and test session (right) after intra-CeA infusions of saline (SAL) or OT in Experiment 1. The data from five rats were excluded from the analysis because of incorrect cannula placement yielding the following group sizes: Groups SAL, $n=9$ and OT, $n=10$. (*) $P<0.05$, main effect of group. (C) Mean (+SEM) percent freezing to the context across the acquisition (left) and test session (right) after intra-BLA infusions of saline (SAL) or OT in Experiment 2. The data from six rats were excluded from the analysis of this experiment because of incorrect cannula placement yielding the following group sizes: Groups SAL, $n=10$ and $\mathrm{OT}, n=8$. (\#) $P<0.05$, main effect of group and trend $\times$ group interaction.

Day 4, and tested, again under extinction, on Day 5. Rats received an infusion of saline (Group SAL) or various doses of OT $(0.6,3$, 15 , and $75 \mathrm{ng}$ ) $10 \mathrm{~min}$ prior to the extinction session on Day 4 and all rats were tested drug free on Day 5 (Fig. 3A). The aims were to determine whether OT exerted a dose-dependent effect on freezing across the extinction session and on the long-term learning produced by that extinction session.

Figure $3 \mathrm{~B}$ shows levels of freezing to the context in the last minute of the second conditioning session on Day 3 (left), the 20 min extinction session on Day 4 (middle), and the 10 min retention test on Day 5 (right). Conditioning was successful: all rats froze after the shock on Day 1, and both before and after the shock on Day 3. There were no statistically significant differences in freezing between the various groups (left panel; all $\left.F \mathrm{~s}_{(1,42)}<2 ; P>0.05\right)$. All rats froze when reexposed to the context on Day 4 . There were clear differences between the groups in overall levels of freezing: those treated with different doses of OT (all groups collapsed) froze more than saline-treated controls, $F_{(1,42)}=10.53 ; P<0.05$, but did not differ from each other, $F \mathrm{~s}_{(1,42)}<2 ; P>0.05$. The levels of freezing declined across the nonshocked exposure, $F_{(1,42)}=74.10 ; P<0.05$, and there were no statistically significant group $\times$ linear trend interactions, $F_{(1,42)}<1.2 ; P>0.05$.

The freezing that was depressed by the end of the extinction session on Day 4 recovered when rats were returned to the context for testing on Day 5 (Fig. 3B right panel). The levels of freezing again declined across the test session, confirmed by the statistically significant linear trend, $F_{(1,41)}=119.60 ; P<0.05$. There were no statistically significant group $\times$ linear interactions, $F \mathrm{~s}_{(1,42)}<2.22 ; P>0.05$, but there were differences between the groups in overall levels of freezing. Specifically, rats infused with OT before the extinction session froze significantly more on test than rats extinguished under vehicle, $F_{(1,42)}=9.13 ; P<0.05$. There were no statistically significant differences among the rats infused with the different doses of OT, $F \mathrm{~s}_{(1,42)}<1.13 ; P>0.05$.

In summary, an infusion of OT into the CeA not only increased expression of conditioned freezing responses and/or impaired within-session extinction, but also impaired the learning that underlies long-term inhibition of freezing responses. Additionally, the effects of OT in the CeA on freezing responses did not vary as a function of doses ranging from 0.6 to $75 \mathrm{ng}$.
Experiment 4: $\mathrm{CeA}$ infusion of OT or a selective OT agonist impairs short- and long-term inhibition of fear responses

In the previous experiment, rats infused with synthetic OT into the CeA froze more than control rats when reexposed to the conditioned context, whereas Viviani et al. (2011) reported that rats infused with a selective OT agonist (7 ng TGOT) into the CeA froze less than control rats when reexposed to a conditioned context. These differing results may be due to the fact that synthetic OT can have nonselective effects on other receptors in the CeA, including vasopressin, which may influence the expression of context-conditioned fear. Accordingly, the present experiment examined the effect of a CeA TGOT infusion on expression of context-conditioned fear using the same protocol and parameters as the previous experiment.

Rats were implanted with bilateral cannulae targeting the CeA. All rats received context conditioning on Days 1 and 3. On Day 4, rats received an intra-CeA infusion of either saline (Group SAL), OT (15 ng; Group OT), or TGOT (7 ng; Group TGOT) 10 min prior to a 20-min extinction session in the context. On Day 5, rats were tested under extinction for fear of the context (Fig. 3A). These doses were chosen based on their effectiveness to respectively increase freezing in Experiment 3 (OT) and reduce freezing in a previous report (TGOT) Viviani et al. 2011).

Figure 3C shows the levels of conditioned freezing in the final minute of the context conditioning session on Day 2, the 20-min extinction session on Day 3 and the 10 min test under extinction on Day 4. All groups showed substantial and equivalent levels of freezing across context conditioning on Day 3, all $F_{\mathrm{s}_{(1,23)}}<1 ; P>0.05$, and a linear decline in freezing across the extinction session on Day $4, F_{(1,23)}=131.14 ; P<0.05$. However, there were clear differences between the groups in overall levels of freezing: Groups OT and TGOT froze significantly more than Group SAL, $F_{(1,23)}=17.91 ; P<0.05$, but did not differ from each other, $F_{(1,23)}<1 ; P>0.05$. The group $\times$ linear trend interactions were not significant, $F_{(1,23)}<1 ; P>0.05$, showing that the differences between the levels of freezing among the groups persisted across extinction session.

The freezing that had been depressed at the end of the extinction session recovered when rats were returned to the context for testing. The levels of this freezing declined across the test, $F_{(1,30)}=42.31 ; P<0.05$, and the rate of this decline was similar among the groups as there were no statistically significant group $\times$ linear trend interactions, $F \mathrm{~s}_{(1,23)}<3.72 ; P>0.05$. However, there were differences among the groups in overall levels of freezing: rats that had been extinguished under a drug (Groups OT and TGOT) froze significantly more than those in Group SAL, $F_{(1,23)}=9.83 ; P<0.05$, and rats in Group OT froze significantly more than those in Group TGOT, $F_{(1,23)}=7.54 ; P<0.05$. The final comparisons confirmed that rats extinguished under OT froze significantly more on test than those in Group Saline, $F_{(1,23)}=17.53$; $P<0.05$, whereas rats extinguished under TGOT did not, $F_{(1,23)}=$ $1.87 ; P>0.05$.

In summary, when infused into the CeA, both OT and TGOT enhanced freezing and/or impaired inhibition of freezing across extinction. However, the drugs had different effects on long-term inhibition of freezing: OT infused into the CeA impaired long- 

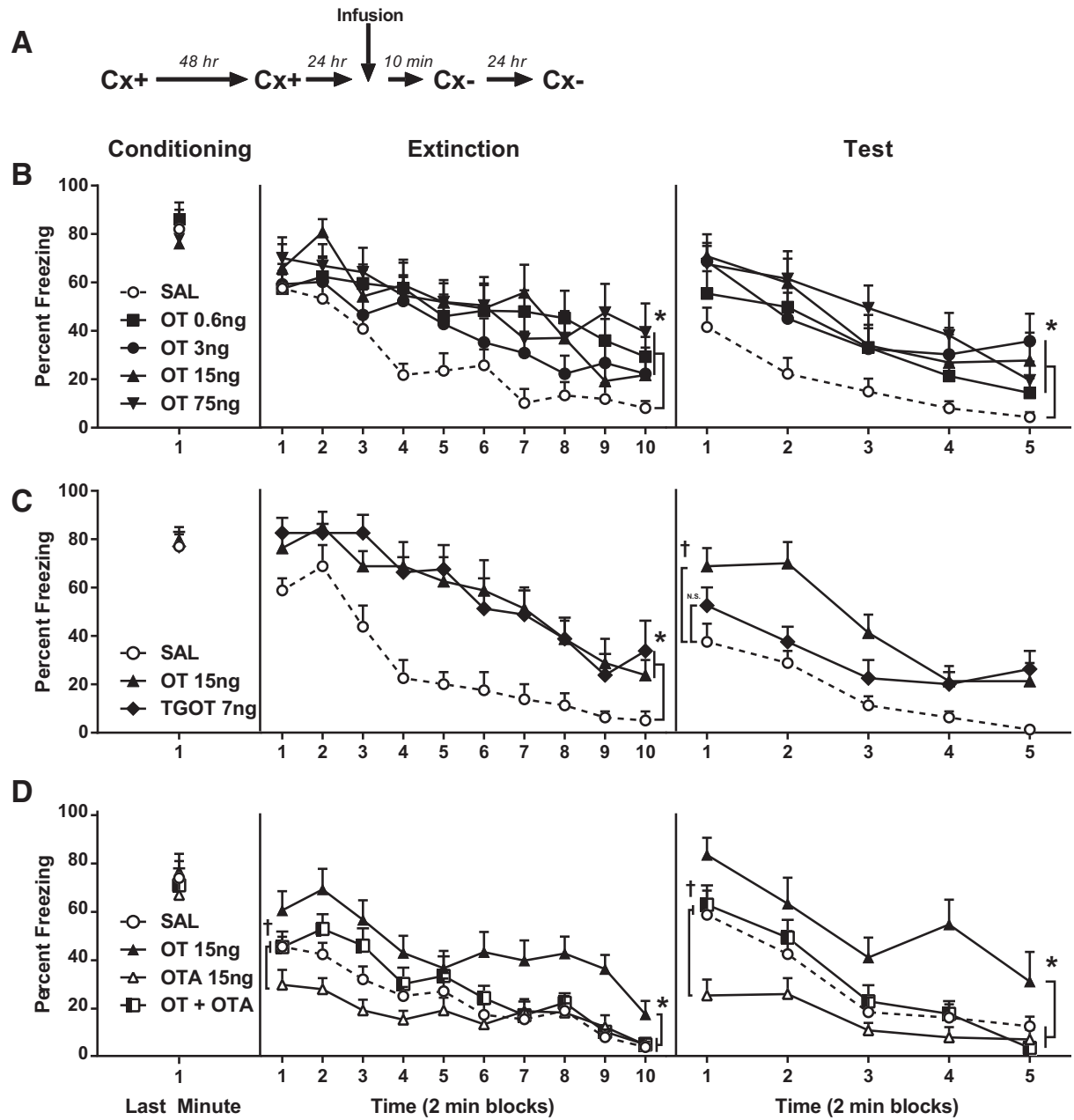

Figure 3. The effects of intra-CeA infusions on extinction of context-conditioned fear. Mean (+SEM) percent freezing to the context in the final minute of the second context-conditioning session (left panel), across the extinction (center panel) and test (right panel) sessions. (A) Timeline of the experimental procedure; $\mathrm{Cx}+$ and $\mathrm{Cx}$ - represent context-shock and context extinction sessions, respectively. (B) Experiment 3 , the effect of preextinction infusions of $\mathrm{OT}$ at various doses. The data from 12 rats were excluded from Experiment 3 because of incorrect cannula placement yielding the following group sizes: Groups SAL, $n=12$, OT $0.6 \mathrm{ng}, n=9$, OT $3 \mathrm{ng}, n=10$, OT $15 \mathrm{ng}, n=8$, and OT $75 \mathrm{ng}, n=8$. ( $\left.{ }^{*}\right) P<0.05$, main effect contrast testing SAL versus all OT groups. (C) Experiment 4, the effect of preextinction infusions of OT and the selective OT agonist (TGOT). The data for 10 rats were excluded from the analysis because of incorrect cannula placement yielding the following group sizes: Group SAL, $n=8$, Group OT $15 \mathrm{ng}, n=10$, Group TGOT $7 \mathrm{ng}, n=8$. In extinction: $(*) P<0.05$, main effect contrast testing SAL versus (OT and TGOT) groups. At test: $(\dagger) P<0.05$, comparison SAL versus OT. (D) Experiment 5 , the effect of the selective OT antagonist alone (OTA) and in conjunction with OT (OT + OTA). The data from 12 rats were excluded from the analysis because of incorrect cannula placement yielding the following group sizes: Group SAL, $n=10$, Group OT, $n=9$, Group OTA, $n=9$ and Group OT + OTA, $n=8$. In extinction: $(*) P<0.05$, main effect of group and group $\times$ trend contrast testing OT 15 ng versus remaining groups. ( $\dagger$ ) $P<0.05$, contrast OTA $15 \mathrm{ng}$ versus (SAL and OT + OTA) groups across the first $10 \mathrm{~min}$ of the extinction session. At test: $\left(^{*}\right) P<0.05$, main effect of group and group $\times$ trend contrast testing OT $15 \mathrm{ng}$ versus remaining groups. $(\dagger) P<0.05$, contrast OTA $15 \mathrm{ng}$ versus (SAL and OT + OTA) groups.

term inhibition but TGOT did not. This result might imply that the effect of CeA OT infusion was due to nonselective OT binding to CeA vasopressin receptors. In contrast to OT, elevated vasopressin has been linked to stress, aggression, and anxiety-related behaviors (Frank and Landgraf 2008), and thus, activation of vasopressin receptors may have an opposing influence on fear conditioning relative to activation of OTr. This possibility is addressed in the next experiment through the use of OT in combination with a selective OTr antagonist.

\section{Experiment 5: The effects of CeA OT are specific to the OT receptor}

This experiment had two aims. The first was to replicate the shortand long-term effects when rats are infused with OT into the CeA before extinction of context-conditioned fear. The second aim was to examine whether these impairments were blocked by co-infusion of OT and the selective OT antagonist desGly- $\mathrm{NH}_{2}-$ $\mathrm{d}\left(\mathrm{CH}_{2}\right) 5\left[\mathrm{D}-\mathrm{Tyr}^{2}, \mathrm{Thr}^{4}\right]$ OVT, OTA. Rats were implanted with bilateral cannula targeting the CeA. All rats received context conditioning on Days 1 and 3. Rats received an intra-CeA infusion of saline (Group SAL), OT (15 ng), OTA (15 ng) or a combination of OT (15 ng) and OTA (75 ng; Group OT + OTA) $10 \mathrm{~min}$ prior to the extinction session on Day 4. A comparable $15 \mathrm{ng}$ dose of OTA was infused alone whereas OT and OTA was combined in a ratio 3:1 for the OT + OTA combination (M Manning, pers. comm.). Rats were tested drug-free under extinction for fear of the context on Day 5 (Fig. 3A).

Figure 3D shows the levels of conditioned freezing in the final minute of the conditioning session on Day 2, across the 20 min extinction session on Day 3 and the 10-min test session under 
Table 1. Designs of Experiments 1-8

\begin{tabular}{|c|c|c|c|c|c|}
\hline Group & Day 1 & Day 2 & Day 3 & Day 4 & Day 5 \\
\hline \multicolumn{6}{|l|}{ Experiment 1 (intra-CeA) } \\
\hline SAL & ${ }^{*} \mathrm{Cx}+$ & $C x-$ & & & \\
\hline OT $75 \mathrm{ng}$ & ${ }^{*} \mathrm{C} x+$ & $C x-$ & & & \\
\hline \multicolumn{6}{|l|}{ Experiment 2 (intra-BLA) } \\
\hline SAL & ${ }^{*} \mathrm{C} x+$ & $C x-$ & & & \\
\hline OT $75 \mathrm{ng}$ & ${ }^{*} \mathrm{Cx}+$ & $\mathrm{Cx}-$ & & & \\
\hline \multicolumn{6}{|l|}{ Experiment 3 (intra-CeA) } \\
\hline SAL & $C x+$ & handle & $C x+$ & ${ }^{*} \mathrm{C} x-$ & $C x-$ \\
\hline OT $0.6 \mathrm{ng}$ & $\mathrm{Cx}+$ & handle & $C x+$ & ${ }^{*} \mathrm{C} x-$ & $C x-$ \\
\hline OT $3 \mathrm{ng}$ & $\mathrm{Cx}+$ & handle & $C x+$ & ${ }^{*} \mathrm{C} x-$ & $C x-$ \\
\hline OT $15 \mathrm{ng}$ & $\mathrm{Cx}+$ & handle & $\mathrm{Cx}+$ & ${ }^{*} \mathrm{Cx}-$ & $\mathrm{Cx}_{-}-$ \\
\hline ОT $75 \mathrm{ng}$ & $C x+$ & handle & $C x+$ & ${ }^{*} \mathrm{Cx}-$ & $C x-$ \\
\hline \multicolumn{6}{|l|}{ Experiment 4 (intra-CeA) } \\
\hline SAL & $C x+$ & handle & $C x+$ & ${ }^{*} \mathrm{Cx}-$ & $C x-$ \\
\hline OT $15 \mathrm{ng}$ & $\mathrm{Cx}+$ & handle & $\mathrm{Cx}+$ & ${ }^{*} \mathrm{Cx}-$ & $\mathrm{Cx}_{-}-$ \\
\hline TGOT 7 ng & $C x+$ & handle & $C x+$ & ${ }^{*} \mathrm{Cx}-$ & $C x-$ \\
\hline TGOT $45 \mathrm{ng}$ & $C x+$ & handle & $C x+$ & ${ }^{*} \mathrm{C} x-$ & $C x-$ \\
\hline \multicolumn{6}{|l|}{ Experiment 5 (intra-CeA) } \\
\hline SAL & $C x+$ & handle & $C x+$ & ${ }^{*} \mathrm{Cx}-$ & $C x-$ \\
\hline OT $15 \mathrm{ng}$ & $C x+$ & handle & $C x+$ & ${ }^{*} \mathrm{C} x-$ & $C x-$ \\
\hline OTA $15 \mathrm{ng}$ & $C x+$ & handle & $C x+$ & $* \mathrm{Cx}-$ & $C x-$ \\
\hline OT $15 \mathrm{ng}$ and OTA $75 \mathrm{ng}$ & $C x+$ & handle & $C x+$ & ${ }^{*} \mathrm{Cx}-$ & $C x-$ \\
\hline \multicolumn{6}{|c|}{ Experiment 6 (intra-CeA) } \\
\hline SAL & $C x+$ & handle & $C x+$ & ${ }^{*} \mathrm{C} x-$ & $C x-$ \\
\hline PRE OT $3 \mathrm{ng}$ & $C x+$ & handle & $C x+$ & ${ }^{*} \mathrm{C} x-$ & $C x-$ \\
\hline POST C & $\mathrm{Cx}+$ & handle & $\mathrm{Cx}+$ & $\mathrm{Cx}-*$ & $C x-$ \\
\hline \multicolumn{6}{|l|}{ Experiment 7 (intra-BLA) } \\
\hline SAL & $C x+$ & handle & $C x+$ & ${ }^{*} \mathrm{C} x-$ & $C x-$ \\
\hline OT 0 & $\mathrm{Cx}+$ & handle & $C x+$ & ${ }^{*} \mathrm{C} x-$ & $C x-$ \\
\hline OT $3 \mathrm{ng}$ & $\mathrm{Cx}+$ & handle & $\mathrm{Cx}+$ & ${ }^{*} \mathrm{Cx}-$ & $C x-$ \\
\hline OT $15 \mathrm{ng}$ & $C x+$ & handle & $C x+$ & ${ }^{*} \mathrm{Cx}-$ & $C x-$ \\
\hline OT $75 \mathrm{ng}$ & $C x+$ & handle & $C x+$ & ${ }^{*} \mathrm{C} x-$ & $C x-$ \\
\hline \multicolumn{6}{|l|}{ Experiment 8 (intra-BLA) } \\
\hline SAL & $C x+$ & handle & $C x+$ & ${ }^{*} \mathrm{Cx}-$ & $C x-$ \\
\hline PRE OT $3 \mathrm{ng}$ & $\mathrm{Cx}+$ & handle & $C x+$ & ${ }^{*} \mathrm{Cx}-$ & $C x-$ \\
\hline POST OT $3 \mathrm{ng}$ & $\mathrm{Cx}+$ & handle & $C x+$ & $\mathrm{Cx}-*$ & $C x-$ \\
\hline OTA $3 \mathrm{ng}$ & $C x+$ & handle & $C x+$ & ${ }^{*} \mathrm{C} x-$ & $C x-$ \\
\hline OT $3 \mathrm{ng}$ and OTA $15 \mathrm{ng}$ & $\mathrm{Cx}+$ & handle & $\mathrm{Cx}+$ & ${ }^{*} \mathrm{Cx}-$ & $C x-$ \\
\hline
\end{tabular}

In each experiment, rats were exposed to pairings of a novel context $(C x)$ and shock $(+)$. Context-conditioned fear was then extinguished $(C x-)$ under drug or vehicle, and finally, rats were tested for retention of extinction when drug-free (i.e., $24 \mathrm{~h}$ after extinction). Time of drug or vehicle infusion is represented by an asterisk (*) before or after a Cx session.

extinction on Day 4. Conditioning was effective; all rats froze after the shock on Day 1 and both before and after the shock on Day 3 . There were no differences among the groups in the levels of freezing, all $F \mathrm{~s}_{(1,32)}<1.13 ; P>0.05$. On Day 4, freezing responses declined in all groups across the extinction session, $F_{(1,32)}=$ 99.36; $P<0.05$. OT enhanced freezing and/or impaired its suppression across extinction: rats in Group OT froze significantly more than those in the remaining groups, $F_{(1,32)}=27.85 ; P<$ 0.05 . There were no statistically significant differences in the levels of freezing among the remaining groups, all $F \mathrm{~s}_{(1,32)}<1.07 ; P>$ 0.05 . There was a statistically significant trend $\times$ group interaction which, from inspection of Figure 3D, was due to a slower decline in freezing by rats in Group OT than by those infused with vehicle (Group SAL) and with the combination of OT and the antagonist OTA (Group OT + OTA), $F_{(1,32)}=7.81 ; P<0.05$. Inspection of Figure 3D also suggests that infusion of the antagonist, OTA, reduced freezing responses across extinction. Indeed, across the first $10 \mathrm{~min}$ of the extinction session, rats in Group OTA froze significantly less than rats in Groups SAL and OT + OTA, $F_{(1,32)}=8.31 ; P<0.05$. The antagonist also blocked the effect of OT on within-session extinction, evidenced by the fact that the level of freezing in Group OT + OTA was equivalent to that in Group SAL, $F_{(1,32)}=1.27 ; P>0.05$.
The levels of freezing across test (right panel) were similar to those observed across extinction. Freezing declined linearly across the test, $F_{(1,32)}=110.55 ; P<0.05$. Rats that had been extinguished under OT (Group OT) froze significantly more than those in the remaining groups, $F_{(1,32)}=16.62 ; P<0.05$, confirming that the drug had impaired long-term suppression of freezing. The levels of freezing did not differ among the remaining groups (Groups $\mathrm{SAL}$, OTA, and OT + OTA), $F \mathrm{~s}_{(1,32)}<3.40 ; P>0.05$. However, there was a statistically significant group $\times$ linear trend interaction which, from inspection of Figure 3D, was due to difference between the groups across the early but not the later stages of the test session, $F_{(1,32)}=9.68 ; P<0.05$. Comparisons of freezing in the first 5 min of testing confirmed that rats in Group OTA froze significantly less than rats in Groups SAL and OT + OTA, $F_{(1,32)}=$ 6.33; $P<0.05$, showing that the antagonist had facilitated longterm suppression of freezing. There were no statistically significant differences between the levels of freezing across the first 5 min of testing by rats in Groups SAL and OT + OTA, $F_{(1,32)}<1$; $P>0.05$, showing that the antagonist had blocked the effect of OT on long-term suppression of freezing.

In summary, when infused into the CeA: (1) OT enhanced expression of conditioned freezing and/or impaired the inhibition of this freezing across extinction; (2) these effects were blocked by coadministration of a highly selective OTr antagonist, OTA; and (3) infusion of OTA alone suppressed expression of conditioned freezing and/or facilitated the inhibition of this freezing across extinction.

\section{The effect of an OTr agonist, antagonist, or their combination on consolidation of extinction learning when infused into the $\mathrm{CeA}$}

\section{Experiment 6: Infusion of OT into the CeA before or after the extinction session impairs long-term reduction of fear responses}

The previous experiments demonstrated that an OT infusion into the CeA before extinction impaired the long-term suppression of freezing responses. This experiment examined whether the longterm impairment was due to an effect of OT on extinction learning or its consolidation. Rats were implanted with bilateral cannulae targeting the CeA. All rats received context conditioning on Days 1 and 3. On Day 4: rats in Group PRE OT received an intra-CeA infusion of OT ( $3 \mathrm{ng}$ ) $10 \mathrm{~min}$ before the extinction session and a saline infusion immediately after that session; those in Group POST OT received an intra-CeA infusion of saline before the extinction session and an OT infusion immediately after that session; finally, those in Group Saline received a saline infusion before and after the extinction session. On Day 5, rats were tested for $10 \mathrm{~min}$ in the context under extinction (Fig. 4A).

Figure 4B shows the levels of freezing to the context in the final minute of context conditioning on Day 1, across the 20-min extinction session on Day 3 and across the 10-min test under extinction on Day 4. Conditioning was successful: all rats froze after the shock on Day 1 and both before and after the shock on Day 3. There were no between-group differences in the levels of freezing, $F_{(1,24)}<1 ; P>0.05$. On Day 4 , freezing declined linearly across the extinction session, $F_{(1,24)}=124.53 ; P<0.05$. There were no statistically significant trend $\times$ group interactions, $F<$ 2. However, rats extinguished under OT (Group PRE OT) froze significantly more than rats extinguished under saline (Groups SAL and POST OT), $F_{(1,24)}=16.63 ; P<0.05$, replicating the effects observed previously. Rats in the latter groups did not differ in their levels of freezing, $F<1$.

On Day 5, freezing declined linearly across the test session, $F_{(1,26)}=79.87 ; P<0.05$. Rats that had been infused with OT into the CeA either before (Group PRE OT) or after (Group POST 


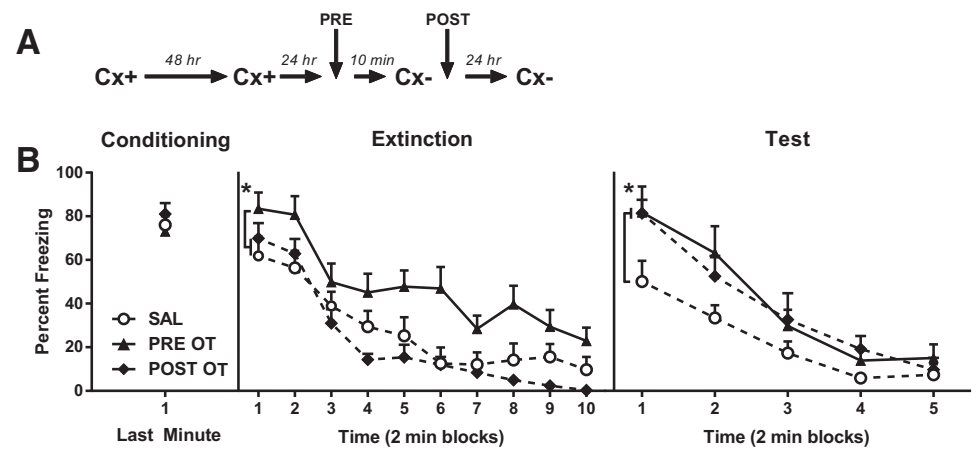

Figure 4. The effects of pre- and post-extinction OT infusions into the CeA. (A) Timeline of the experimental procedure; $\mathrm{Cx}+$ and $\mathrm{Cx}$ - represent context-shock and context extinction sessions, respectively. (B) Mean (+SEM) percent freezing to the context in Experiment 6 in the final minute of the second context conditioning session (left panel), across the extinction (center panel), and test (right panel) sessions. The data from nine rats were excluded from the analysis because of incorrect cannula placement yielding the following group sizes: Group SAL, $n=9$, Group PRE OT, $n=10$, Group POST OT, $n=8$. In Extinction: $\left(^{*}\right) P<0.05$, main effect contrast testing PRE OT versus (POST OT and SAL) groups. At test: $(*) P<0.05$, main effect contrast testing SAL versus (PRE OT and POST OT) groups.

OT) the extinction session froze significantly more than rats that had been extinguished under saline (Groups SAL), $F_{(1,24)}=6.97$; $P<0.05$. There was no significant difference in freezing between Groups PRE OT and POST OT, $F<1$, and no statistically significant trend $\times$ group interactions, $F \mathrm{~s}<3$.

In summary, this experiment again confirmed that an infusion of OT into the CeA enhanced the expression of conditioned freezing responses and/or impaired the suppression of these responses across extinction. Furthermore, it confirmed that a CeA OT infusion impaired the long-term suppression of freezing (as evidenced by the results from the drug-free retention test) and showed that this impairment was due to a disruption of extinction consolidation. Taken together, these findings suggest that OT in the CeA impairs both within-session extinction, and consolidation of the learning produced by extinction.

\section{The effect of an OTr agonist or antagonist on extinction learning and consolidation when infused into the BLA}

\section{Experiment 7: BLA infusion of OT facilitates short- and long-term reduction of fear}

The next set of experiments examined the effects of OT when infused into the BLA on the expression of context-conditioned freezing, its suppression across the extinction session, and the retention of this suppression on the subsequent drug-free test. The present experiment involved five groups: rats infused with saline into the BLA before extinction and those infused with a $0.6,3,15$, or $75 \mathrm{ng}$ dose of OT before extinction. Rats were implanted with bilateral cannulas targeting the BLA. All rats were subjected to context conditioning on Days 1 and 3. Rats received an intra-BLA infusion of either saline or one of the four doses of OT 10 min prior to the extinction session on Day 4. All rats were tested drug-free in the conditioned context for 10 min under extinction on Day 6 (Fig. 5A).

Figure $5 \mathrm{~B}$ shows the levels of conditioned freezing on the final minute of context conditioning on Day 2, across the 20-min extinction session on Day 3, and the 10-min test under extinction on Day 4. Conditioning was successful; all rats froze after the shock on Day 1 and both before and after the shock on Day 3 . There were no significant differences between the groups in the levels of freezing, $F \mathrm{~s}_{(1,36)}<2.12 ; P>0.05$. Freezing declined across the extinction session on Day $4, F_{(1,36)}=136.12 ; P<$ 0.05 . There was a statistically significant group $\times$ trend interac- tion, $F_{(1,36)}=14.60 ; \quad P<0.05$, which, from inspection of Figure $5 \mathrm{~B}$, was due the greater level of initial freezing and the more rapid change in that level across the session among rats infused with saline (Group SAL) than those infused with the drug. Overall, and in contrast to the effect of a CeA OT infusion, rats that received an infusion of OT in the BLA before the extinction session (Groups OT 0.6 ng, OT 3 ng, OT 15 ng, and OT $75 \mathrm{ng}$ ) froze significantly less than rats infused with saline (Group SAL), $F_{(1,36)}=11.52 ; P<0.05$, but did not differ from each other, $F \mathrm{~s}_{(1,36)}<$ $1.61 ; P>0.05$.

During the test session on Day 5 , freezing again declined linearly across the test session, $F_{(1,36)}=123.90 ; P<$ 0.05 . Rats that had been extinguished under saline froze significantly more than rats that had been extinguished under OT, $F_{(1,36)}=7.29 ; P<0.05$, showing better retention of extinction among the drug-treated rats. There was also a dose effect such that rats extinguished under higher doses of OT (Groups OT3 ng, OT15 $\mathrm{ng}$, and OT75 ng) froze significantly less than those extinguished under the lowest dose (Group OT0.6 ng), $F_{(1,36)}=6.95 ; P<0.05$. A statistically significant group $\times$ trend interaction showed that this difference in retention among the drug groups was more pronounced during the early stage of the test session, $F_{(1,36)}=$ $19.82 ; P<0.05$. No other main effects or interactions were significant, $F \mathrm{~s}<4.3$.

In contrast to its effects on the CeA, an infusion of OT into the BLA not only suppressed expression of conditioned freezing responses and/or facilitated within-session extinction, but also facilitated the learning that underlies long-term inhibition of freezing responses. The acute effects of BLA OT on freezing responses did not vary as a function of doses ranging from 0.6 to $75 \mathrm{ng}$. However, the drug-free retention test provided some evidence that the effects of BLA OT varied with dose, as rats extinguished under the higher doses of OT froze less than rats extinguished under the lowest dose.

\section{Experiment 8: The effects of BLA OT are specific to the OT receptor}

The present experiment had two aims. The first was to determine whether the facilitation of long-term extinction produced by higher doses of BLA OT is due to enhanced acquisition and/or consolidation of extinction learning. The second aim was to assess whether BLA OT facilitates within-session and long-term extinction by acting on OT receptors. This was assessed by co-infusion of OT with the selective antagonist desGly- $\mathrm{NH}_{2}-\mathrm{d}\left(\mathrm{CH}_{2}\right) 5[\mathrm{D}-$ $\mathrm{Tyr}^{2}, \mathrm{Thr}^{4}$ ]OVT (OTA). Rats were implanted with bilateral cannulas targeting the BLA and subjected to context conditioning on Days 1 and 3. Rats in four groups received an intra-BLA infusion of either saline, OT (3 ng), OTA (3 ng), or a combination of OT (3 ng) and OTA (15 ng) $10 \mathrm{~min}$ before the extinction session on Day 4. Rats in the final group received an infusion of OT immediately following the extinction session. The $3 \mathrm{ng}$ dose was selected based on the results from the previous experiment. As in the CeA experiments, a comparable $3 \mathrm{ng}$ dose of OTA was infused alone whereas OT and OTA was combined in a ratio 3:1 for the OT + OTA combination (M Manning, pers. comm.). Rats were tested drug-free for 10 min under extinction on Day 5 (Fig. 5C).

Figure 5D shows the levels of freezing across the final minute of the conditioning session on Day 2, across the 20 min extinction 

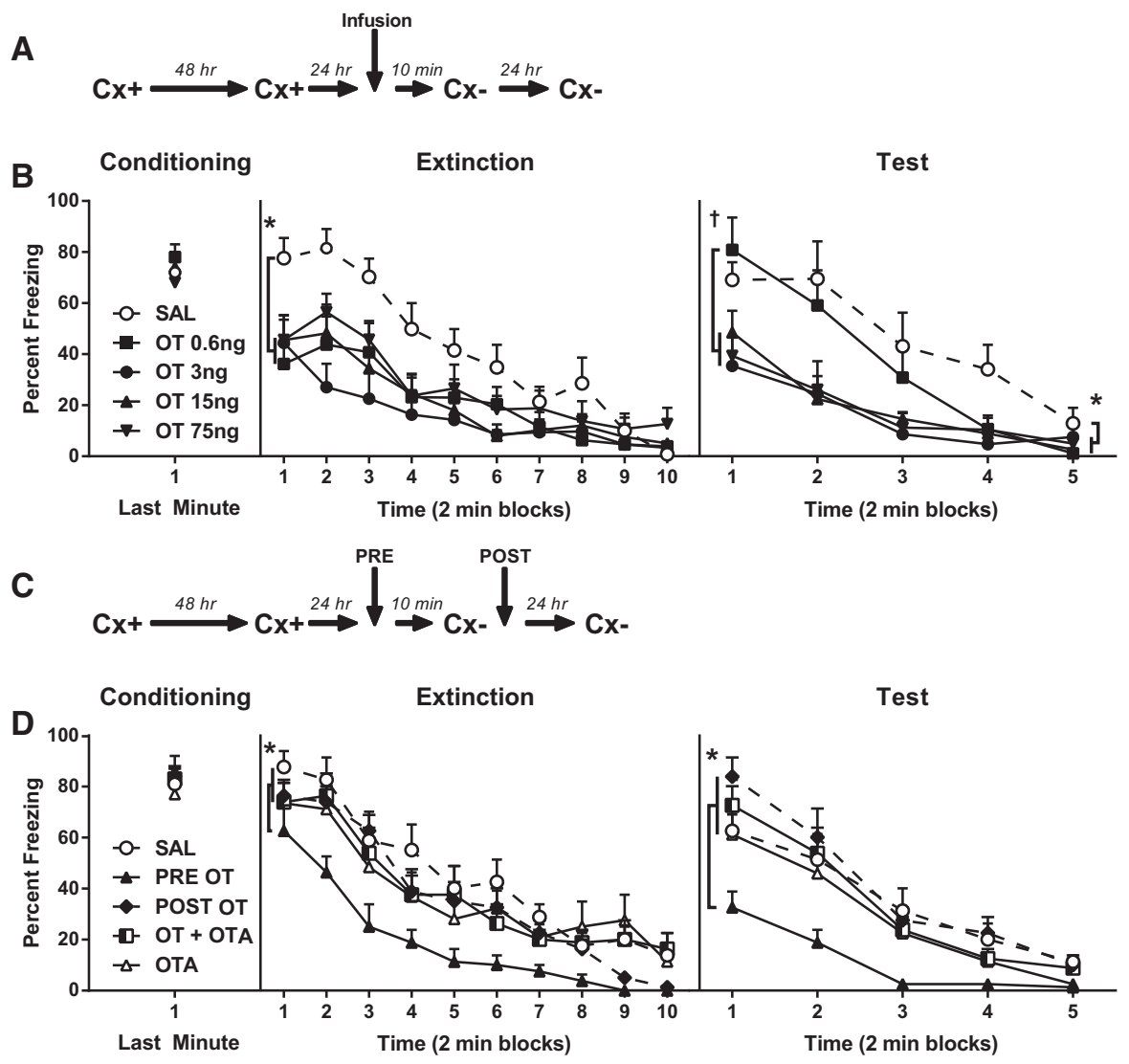

Figure 5. The effects of intra-BLA infusions on extinction of context-conditioned fear. Mean (+SEM) percent freezing to the context in the final minute of the second context-conditioning session (left panel), across the extinction (center panel) and test (right panel) sessions. $(A, C)$ Timeline of the experimental procedures; $\mathrm{Cx}+$ and $\mathrm{Cx}$ - represent context-shock and context-extinction sessions respectively. $(B)$ Experiment 7 , the effect of preextinction infusions of OT at various doses. The data from 18 rats were excluded from this experiment because of incorrect cannula placement yielding the following group sizes: group SAL, $n=8$, group OT $0.6 \mathrm{ng}, n=9$, group OT $3 \mathrm{ng}, n=8$, group OT $15 \mathrm{ng}, n=8$, group OT $75 \mathrm{ng}, n=9$. In extinction: $\left(^{*}\right) P<0.05$, main effect contrast testing SAL versus (PRE OT and POST OT) groups. At test: $(*) P<0.05$, main effect contrast testing SAL versus $(0.6,3,15$, and $75 \mathrm{ng}$ OT) groups. $(\dagger) P<0.05$, main effect of group and group $\times$ trend contrast testing $0.6 \mathrm{ng}$ OT versus $(3,15$, and $75 \mathrm{ng}$ OT) groups. (D) Experiment 8 , the effect of pre- and post-extinction OT infusions, and the effect of the selective OT antagonist alone (OTA) and in conjunction with OT (OT + OTA). The data from 11 rats were excluded from the analysis because of incorrect cannula placement yielding the following group sizes: Group SAL, $n=10$, Group PRE OT, $n=9$, Group OT + OTA, $n=8$, Group OTA, $n=9$, Group POST OT, $n=10$. In extinction: $\left(^{*}\right) P<0.05$, main effect contrast testing PRE OT versus (SAL, POST OT, OT + OTA, and OTA) groups. At test: $\left(^{*}\right) P<0.05$, main effect of group and group $\times$ trend contrast testing PRE OT versus (SAL, POST OT, OT + OTA, and OTA) groups.

session on Day 3, and the 10 min test on Day 4. Conditioning was successful: all rats froze after the shock on Day 1 and both before and after the shock on Day 3. There were no significant differences in the levels of freezing among the groups, all $F \mathrm{~s}_{(1,41)}<1.5 ; P>$ 0.05 . Freezing declined linearly across the extinction session, $F_{(1,41)}=235.35 ; P<0.05$ and there were no statistically significant group $\times$ trend interactions, all $F \mathrm{~s}_{(1,41)}<1.82 ; P>0.05$. However, rats extinguished under OT (Group PRE OT) froze significantly less than those in the remaining groups, $F_{(1,41)}=18.67$; $P<0.05$, which did not differ, $F \mathrm{~s}_{(1,41)}<1.13 ; P>0.05$. The final comparisons showed that rats extinguished under OT froze significantly less than those extinguished under saline (Group SAL) or a combined infusion of OT and the antagonist (Group OT + OTA), $F_{(1,41)}=18.73 ; P<0.05$. There were no significant differences between the latter groups $F_{(1,41)}<1.13 ; P>0.05$.

The freezing that had been depressed at the end of the extinction session on Day 4 recovered on the test session on Day 5. This freezing again declined linearly across the test session, $F_{(1,41)}=$ 268.06; $P<0.05$. Rats that had been extinguished under OT (Group OT) froze significantly less than rats in the remaining groups, $F_{(1,41)}=23.91 ; P<0.05$. A significant group $\times$ linear trend interaction showed that this difference between Group OT and the remaining groups was most pronounced across the early stages of the test session, $F_{(1,41)}=13.29 ; P<0.05$. There were no other significant differences or interactions involving the remaining groups, $F \mathrm{~s}_{(1,41)}<3.01 ; P>0.05$.

In summary, this experiment again showed that an infusion of OT into the BLA suppressed conditioned freezing and facilitated the long-term suppression of this response. These effects of BLA OT on conditioned freezing were due to activation of OT receptors, as they were blocked by coadministration of a highly selective OTr antagonist, which had no effect on conditioned freezing when administered on its own. Finally, a post-session infusion of OT into the BLA had no effect on consolidation of extinction learning.

\section{Discussion}

Oxytocin (OT) has been implicated in a variety of social behaviors, e.g., pair mating, social affiliation, social memory, and maternal aggression (for review, see Lee et al. 2009). It has been suggested 
that OT facilitates these behaviors by reducing anxiety (e.g., McCarthy et al. 1996; Bale et al. 2001; Kirsch et al. 2005; Domes et al. 2007; Petrovic et al. 2008; Zoicas et al. 2014; for review, see Neumann 2008; Insel 2010; Neumann and Landgraf 2012). In the present study, we examined how manipulation of central OT signaling influences various aspects of clinical anxiety using a laboratory model. Consistent with other studies, we showed that central infusion of OT influences the acquisition, expression, and extinction of conditioned fear in rats (e.g., Toth et al. 2012). However, we have additionally shown that manipulation of OT signaling in discrete nuclei of the amygdala, the BLA or CeA, has contrasting effects on these phenomena.

In the CeA, OT impaired acquisition of context-conditioned fear when infused before context-shock pairings, evident in lower levels of freezing (relative to controls) when rats were reexposed to the context (Experiment 1); and enhanced expression of context conditioned fear when infused before context reexposure (i.e., the extinction session; Experiment 3). Enhanced fear expression was also observed following a presession infusion of the selective OTr agonist, TGOT (Experiment 4). This enhanced expression of conditioned fear by TGOT was blocked by coadministration of the highly selective OTr antagonist, OTA (Experiment 5), which on its own had the opposite effect to TGOT: OTA suppressed conditioned fear responses (Experiment 5). These results have two implications. The first is that the observed effects of CeA OT on acquisition and expression of context-conditioned fear were due to its activation of OTr, rather than to activation of vasopressin and/or other receptors. This conclusion is consistent with a recent report that a CeA infusion of a selective OTr agonist impaired acquisition of context-conditioned freezing (Lahoud and Maroun 2013). The second implication of these results is that changes in CeA OT signaling exert bidirectional effects on expression of context-conditioned fear: it is enhanced by increases in CeA OT signaling, but suppressed by decreases in CeA OT signaling. Finally, an infusion of OT into the CeA either before or after an extinction training session resulted in high levels of freezing on the subsequent drug-free retention test (Experiment 6). This result shows that OT signaling in the CeA influences not just the expression of fear, but additionally, processes that are critical for retaining inhibition of fear between extinction training and test, e.g., consolidation of extinguished fear responses.

In the BLA, OT also impaired acquisition of context-conditioned fear when infused before context-shock pairings (Experiment 2). The fact that OT had the same effect when infused into the CeA before context-shock pairings implies that any increase in amygdala OT signaling impair acquisition of conditioned fear. OT not only impaired acquisition of conditioned fear, it also suppressed fear expression when infused in the BLA before extinction training at doses ranging from $0.6 \mathrm{ng} / 0.3 \mu \mathrm{L}$ to $75 \mathrm{ng} / 0.3$ $\mu \mathrm{L}$ (Experiment 7). This result is in direct contrast to that obtained when OT was infused into the CeA; that infusion enhanced expression of context-conditioned fear and/or impaired its extinction. OT infused into the BLA also resulted in better long-term extinction, evidenced by the fact that freezing remained suppressed when rats were tested drug-free. Critically, the short and long-term facilitation of extinction by a BLA infusion of OT were blocked by coadministration of the OTr antagonist, demonstrating that the facilitation was due to activation of OTr in the BLA. Finally, it is worth noting that the contrasting effects of OT when infused into either the CeA or BLA allay any potential concerns relating to diffusion of the drug from the targeted nuclei into the other. These contrasting effects imply that, if anything, diffusion of OT from one amygdala nucleus into the other would have opposed the facilitative (CeA) or suppressive (BLA) effects of OT on conditioned freezing.
Some of the present results appear to conflict with other recent findings. First, in contrast to the impairment of conditioned fear observed in Experiment 2, Lahoud and Maroun (2013) reported that a BLA infusion of OT or a selective OTr agonist (WAY267474 or TGOT) enhanced acquisition of context-conditioned fear. Second, in contrast to the increased expression of conditioned fear and/or the impairment in short-term extinction observed in Experiment 4, Viviani et al. 2011 reported that a CeA infusion of TGOT massively suppressed the expression of contextconditioned fear. One way in which the present study differed from the Viviani et al. and Lahoud and Maroun studies is in the levels of fear produced by the context-shock pairings. In both of the earlier studies, there was very little evidence for any decline in freezing across the first extinction session, and hence, the average level of freezing across this session was $>70 \%$. In the present study, rats entered the first (and only) extinction session freezing at $\sim 60 \%-70 \%$, but freezing rapidly declined to low levels by the end of the session, implying a lower level of conditioning. This difference in levels of context fear conditioning between studies suggests that the effects of intra-amygdala OT on acquisition, expression, and extinction of context-conditioned fear vary depending on both the level of fear and the specific nucleus into which OT is infused. Consistent with this possibility, there is evidence that therapeutic effects of OT vary depending on baseline anxiety levels in certain clinical populations (Bartz et al. 2010; for review, see Bartz et al. 2011).

What are the mechanisms by which OT acts in the CeA and BLA to influence acquisition, expression, and extinction of conditioned fear? It has been previously shown that increasing OT signaling in the CeA differentially influences expression of behavioral and autonomic fear responses (Viviani et al. 2011). Based on these findings, it has been suggested that OT acts in the CeA to regulate selection of active versus passive fear responses (e.g., vigilance versus freezing). The focus in this respect has been on OT effects in the lateral region of the CeA (CeL). Here, GABAergic interneurons (Type 1 cells) tonically inhibit CeL projection neurons, which express OTr (Type 2 cells) (Gozzi et al. 2010; Viviani et al. 2011; Knobloch et al. 2012; Stoop 2012). There are two types of $\mathrm{CeL}$ projections. One is to the ventral forebrain cholinergic system, which has been implicated in coordination of active fear responses via its effects on cortical arousal (Gozzi et al. 2010). The other projection is to the medial region of the CeA (CeM), which coordinates passive fear responses via its effects on downstream targets in the midbrain and hypothalamus (Carrive et al. 2000; Ehrlich et al. 2009; Haubensak et al. 2010; see also Penzo et al. 2014). These circuitries suggest that, under conditions of low or moderate fear, OT in the CeA maintains passive fear responses by decreasing activation of CeL projection neurons. This would simultaneously increase the excitatory influence of CeM over its midbrain targets (hence more passive fear) and decrease cholinergic innervation of neocortex (hence less active fear). Conversely, under conditions of high fear, OT in the CeA may trigger a shift from passive to active fear responses by increasing activation of CeL projection neurons, thereby reducing the excitatory influence of CeM over its midbrain targets (hence less passive fear) and increasing cholinergic activation of cortical circuits (hence more active fear).

However, the present findings show that OT in the CeA is not just involved in coordination of fear responses. Acquisition of context-conditioned fear was impaired when OT was infused into the CeA immediately before context-shock pairings; and extinction of context-conditioned fear was disrupted when OT was infused into the CeA immediately after the extinction training session. Thus, in addition to any role in coordination of fear responses, OT appears to regulate plastic changes in CeA that code for both acquisition and extinction of context-conditioned fear. 
OT may regulate these changes through its effects on GABA signaling in CeL (Huber et al. 2005). Both the acquisition and extinction of conditioned fear have been shown to be impaired by increases in CeA GABA signaling via infusion of the GABA-A agonist, muscimol (Wilensky et al. 2006; Ciocchi et al. 2010).

In the BLA, there are two potential mechanisms by which OT signaling might influence fear-related behavior. These mechanisms correspond to distinct populations of BLA neurons that have been implicated in expression and inhibition of conditioned fear, respectively (Herry et al. 2008). Specifically, increases in BLA OT may suppress fear expression and facilitate fear extinction by reducing activation of fear neurons, increasing activation of extinction neurons, or through a combination of these effects; thereby, reducing the capacity of the conditioned stimulus to activate intrinsic amygdala pathways that usually respond to danger (Likhtik et al. 2008; Amir et al. 2011). However, at present, these putative mechanisms are necessarily speculative, as it remains to determine whether fear neurons and/or extinction neurons express OTr, the electrophysiological consequences of their activation, and why these consequences might vary with the strength of conditioning (c.f., Lahoud and Maroun 2013).

In summary, the present study has shown that the effects of centrally administered OT on fear-related behavior vary depending on where it is administered in the brain (e.g., Toth et al. 2012; Lahoud and Maroun 2013), and specifically, the amygdala. Increasing OT signaling in the CeA impaired acquisition of context-conditioned fear, but enhanced expression of this fear and impaired its extinction. In contrast, increasing OT signaling in the BLA impaired acquisition of context-conditioned fear, suppressed expression of this fear and facilitated its extinction. We suggest that the levels of conditioned fear may interact with OT signaling in specific amygdala nuclei to determine the effects on the acquisition and expression of fear as well as those on shortand long-term fear inhibition; effects which may be important for the therapeutic use of OT (Bartz et al. 2010).

\section{Materials and Methods}

\section{Subjects}

Subjects were experimentally naïve, male, outbred Wistar rats (268-413 g) obtained from a commercial supplier (Animal Resources Centre). They were housed in plastic boxes $(67 \mathrm{~cm}$ length $\times 40 \mathrm{~cm}$ width $\times 22 \mathrm{~cm}$ height) with food and water continuously available. There were eight rats per box. The boxes were located in a climate controlled colony room (lights on at 7:00 a.m.). All experimental procedures were approved by the Animal Care and Ethics Committee at the University of New South Wales and in accordance with the National Institutes of Health Guidelines for the Care and Use of Laboratory Animals, revised 1996.

\section{Surgery}

Rats were anesthetized with $100 \mathrm{mg} / \mathrm{mL}$ of ketamine (Ketapex; Apex Laboratories), administered at a dose of $1.0 \mathrm{~mL} / \mathrm{kg}$ intraperitoneal (i.p.), in combination with a muscle relaxant, xylazine (20 $\mathrm{mg} / \mathrm{mL}$ ) at a dosage of $0.3 \mathrm{~mL} / \mathrm{kg}$ (Rompun; Bayer). Anesthetized rats were positioned on a stereotaxic apparatus (Kopf Instruments, and two guide cannula (26 gauge, $11 \mathrm{~mm}$ in length, Plastics One) were implanted through holes drilled in both hemispheres of the skull. The tips of the guide cannulas were aimed bilaterally at the BLA or CeA using the following coordinates: BLA: $2.6 \mathrm{~mm}$ posterior to bregma, $4.8-5 \mathrm{~mm}$ lateral to the midline, and 7.7-7.9 ventral to the skull; CeA: $2.6 \mathrm{~mm}$ posterior to bregma, $4.0-4.2 \mathrm{~mm}$ lateral to the midline, and 7.6 ventral to the skull. The guide cannulas were secured to the skull with three jeweler's screws and dental cement. A dummy cannula was kept in each guide at all times other than during microinjections. Immediately after the surgical procedure, rats received an i.p. injection of a prophylactic $(0.3 \mathrm{~mL})$ dose of $300 \mathrm{mg} / \mathrm{kg}$ solution of procaine penicillin. Rats were allowed $4 \mathrm{~d}$ to recover from surgery, during which time they were handled and weighed daily.

\section{Drug infusions}

The neuropeptide oxytocin was obtained from Sigma and dissolved in nonpyrogenic saline $(0.9 \% \mathrm{wt} / \mathrm{vol} . \mathrm{NaCl})$ to achieve final concentrations of $0.6 \mathrm{ng} / 0.3 \mu \mathrm{L}, 3 \mathrm{ng} / 0.3 \mu \mathrm{L}, 15 \mathrm{ng} / 0.3 \mu \mathrm{L}$, and $75 \mathrm{ng} / 0.3 \mu \mathrm{L}$. The OT solution or nonpyrogenic saline was infused directly into the BLA or CeA across $3 \mathrm{~min}$. The oxytocin antagonist desGly- $\mathrm{NH}_{2}-\mathrm{d}\left(\mathrm{CH}_{2}\right)_{5}\left[\mathrm{D}-\mathrm{Tyr}^{2}, \mathrm{Thr}^{4}\right] \mathrm{OVT}$ (OTA) was dissolved in nonpyrogenic saline to achieve final concentrations of $3 \mathrm{ng} / 0.3 \mu \mathrm{L}, 15 \mathrm{ng} / 0.3 \mu \mathrm{L}, 75 \mathrm{ng} / 0.3 \mu \mathrm{L}$. OT and OTA were combined at concentrations 3 and $15 \mathrm{ng}$, respectively, for BLA experiments and 15 and $75 \mathrm{ng}$, respectively, for CeA experiments.

Drug or saline was infused bilaterally into the BLA or CeA 10 min before or immediately following the extinction session by inserting a 33 gauge internal infusion cannulas into each guide cannula. The internal cannulas were connected to a $25 \mu \mathrm{L}$ glass syringe attached to an infusion pump (Harvard Apparatus) and projected an additional $1 \mathrm{~mm}$ ventral to the tip of the guide cannula. A total volume of $0.3 \mu \mathrm{L}$ was delivered in both sides at a rate of $0.1 \mu \mathrm{L} / \mathrm{min}$. The internal cannula was left in place for a further minute after infusion. The cannula was then removed and replaced with the dummy cannula. All rats were preexposed to this procedure one day before infusion by removing the dummy cannula and running the infusion pump for $3 \mathrm{~min}$. This was done in order to familiarize the rats with the procedure and minimize any effects of its novelty.

\section{Histology}

After completing behavioral testing, rats were injected with a lethal dose of sodium pentobarbital, decapitated, and their brains removed. The brains were sectioned coronally at $40 \mu \mathrm{m}$ through the CeA and BLA. Every third section was collected on a slide and stained with cresyl violet. The location of cannula tips was determined under a microscope by two trained observers using the boundaries defined by Paxinos and Watson (1997). Each experiment started with $n=12$ per group. Rats with inaccurate cannula placements were excluded from the statistical analysis. In total, 57 rats were excluded from the five CeA experiments, and 44 rats were excluded from the three BLA experiments.

\section{Behavioral apparatus}

Training and testing took place in four chambers $(23.5 \mathrm{~cm}$ depth $\times 20.5 \mathrm{~cm}$ width $\times 19.5 \mathrm{~cm}$ height). Their side walls were constructed of clear Perspex, and their end walls and lids of aluminum. The floor was made of stainless steel rods, $2 \mathrm{~mm}$ in diameter, spaced $13 \mathrm{~mm}$ apart, center to center. A tray below the floor contained bedding material. Each chamber was enclosed in a sound- and light-attenuating shell whose floor, ceiling, and walls were painted black. The background noise level of the room was $50 \mathrm{~dB}$ measured by a digital sound level meter (Dick Smith Electronics).

A custom-built constant-current shock generator, capable of delivering unscrambled alternating current $50-\mathrm{Hz}$ shock to the floor of each chamber, was used for the presentation of a $1 \mathrm{sec}$ duration shock at $0.8 \mathrm{~mA}$ intensity. The floor of each chamber was cleaned with a solution of acetic acid (1\%) to eliminate any residue and provide a distinctive odor after removal of each rat at the end of a session. Illumination for each chamber was provided by an infrared light source $(940 \pm 25 \mathrm{~nm})$. A camera mounted on the back wall of each shell recorded the behavior of each rat. Each camera was connected to a monitor and DVD recorded located in another room of the laboratory. This room contained the computer that controlled stimulus presentations via the appropriate software (LabView, National Instruments). 


\section{Procedures}

\section{Preexposure}

Rats were exposed to the chambers for 2 min each day across four days in order to reduce any neophobia and to increase contextconditioned fear (Fanselow 1986; Kiernan and Westbrook 1993).

\section{Acquisition experiments}

Rats were exposed to a single session of context fear conditioning on Day 1. Each rat was shocked twice $(0.8 \mathrm{~mA}$ intensity $\times 1 \mathrm{sec}$ duration): the first shock occurred 1 min after placement in the chamber, the second occurred 3 min after placement in the chamber. Rats remained in the chamber for an additional 2 min after the second shock, yielding a session of length $5 \mathrm{~min}$. Six hours later, in the colony room, rats that had received a drug infusion into the CeA (Experiment 1) or BLA (Experiment 2) received a saline infusion and rats that had received a saline infusion now received a drug infusion into the CeA (Experiments 1) or BLA (Experiment 2) in order to control for any effects of the drug per se on subsequent test performance. Acquisition of contextconditioned fear was then tested in a single session on Day 2 . The session was conducted under conditions of extinction and lasted $10 \mathrm{~min}$.

\section{Expression and extinction experiments}

Rats received two sessions of context fear conditioning. On Day 1, each rat was placed into a chamber and after $1 \mathrm{~min}$ a single footshock $(0.8 \mathrm{~mA}$ intensity $\times 1$-sec duration) was delivered through the grid floor. Rats remained in the chamber for a further $2 \mathrm{~min}$ before being removed and returned to the colony room. On Day $3,48 \mathrm{~h}$ later, all rats were returned to the chambers for a second conditioning session identical to that on Day 1. On Day 4, $24 \mathrm{~h}$ after the second conditioning session, rats were exposed to the chambers for $20 \mathrm{~min}$ in the absence of footshock. Six hours later, in the colony room, rats that had received a drug infusion into the CeA (Experiments 3-6) or BLA (Experiments 7-8) received a saline infusion and rats that had received a saline infusion now received a drug infusion into the CeA (Experiments 3-6) or BLA (Experiments 7-8) in order to control for any effects of the drug per se on subsequent test performance. On Day 5, all rats were tested in the context for $10 \mathrm{~min}$ in the absence of drug, saline, or shock.

\section{Data collection and analysis}

Freezing was used to assess conditioned fear. It was defined as the absence of all movement except those related to breathing (Fanselow 1980). Each rat was observed every 2 sec and scored as either "freezing" or "not freezing" by two observers, one of whom was naïve to group allocation. A percentage score was calculated for the proportion of the total observations scored as freezing for each rat. There was a high degree of agreement between the two observers, with a Pearson product moment correlation $>0.90$. Any disagreement was resolved in favor of the score by the naïve observer. Data were analyzed with a planned contrast testing procedure (Hays 1963). In cases where the set of contrasts was orthogonal (Experiments 1, 2, 3, 6, and 7), the Per Contrast Error Rate was maintained at $\alpha=0.05$. In the cases where the set of contrasts was nonorthogonal (Experiments 4, 5, and 8), a Bonferroni correction was used to control the Per Family Error Rate coherently at $\alpha=0.05$ (Betz and Gabriel 1978; Betz and Levin 1982; Bird 2004).

\section{Acknowledgments}

This research was supported by a grant from the Australian National Health \& Medical Research Council and by a scholarship to the first author from Brain Sciences Institute UNSW. The authors thank Maurice Manning for generously providing the OT receptor antagonist desGly- $\mathrm{NH}_{2}-\mathrm{d}\left(\mathrm{CH}_{2}\right)_{5}\left[\mathrm{D}-\mathrm{Tyr}^{2}, \mathrm{Thr}^{4}\right] \mathrm{OVT}$.

\section{Competing interest statement}

The authors declare no competing financial interests.

\section{References}

Amir A, Amano T, Pare D. 2011. Physiological identification and infralimbic responsiveness of rat intercalated amygdala neurons. J Neurophysiol 105: 3054-3066.

Bale TL, Davis AM, Auger AP, Dorsa DM, McCarthy MM. 2001. CNS region-specific oxytocin receptor expression: importance in regulation of anxiety and sex behavior. J Neurosci 21: 2546-2552.

Bartz JA, Zaki J, Ochsner KN, Bolger N, Kolevzon A, Ludwig N, Lydon JE. 2010. Effects of oxytocin on recollections of maternal care and closeness. Proc Natl Acad Sci 107: 21371-21375.

Bartz JA, Zaki J, Bolger N, Ochsner KN. 2011. Social effects of oxytocin in humans: context and person matter. Trends Cogn Sci 15: 301-309.

Betz MA, Gabriel KR. 1978. Type IV errors and analysis of simple effects. I Educ Stat 3: $121-143$.

Betz MA, Levin JR. 1982. Coherent analysis-of-variance hypothesis testing strategies: a general approach. J Educ Stat 7: 193-206.

Bird KD. 2004. Analysis of variance via confidence intervals. Sage Publications, London.

Carrive P, Lee J, Su A. 2000. Lidocaine blockade of amygdala output in fear-conditioned rats reduces Fos expression in the ventrolateral periaqueductal gray. Neuroscience 95: 1071-1080.

Ciocchi S, Herry C, Grenier F, Wolff SB, Letzkus JJ, Vlachos I, Ehrlich I, Sprengel R, Deisseroth K, Stadler MB, et al. 2010. Encoding of conditioned fear in central amygdala inhibitory circuits. Nature 468: $277-282$.

Domes G, Heinrichs M, Gläscher J, Büchel C, Braus DF, Herpertz SC. 2007. Oxytocin attenuates amygdala responses to emotional faces regardless of valence. Biol Psychiatry 62: 1187-1190.

Ehrlich I, Humeau Y, Grenier F, Ciocchi S, Herry C, Lüthi A. 2009. Amygdala inhibitory circuits and the control of fear memory. Neuron 62: $757-771$.

Fanselow MS. 1980. Conditioned and unconditional components of post-shock freezing. Pavlov J Biol Sci 15: 177-182.

Fanselow MS. 1986. Conditioned fear-induced opiate analgesia: a competing motivational state theory of stress analgesia. Ann N Y Acad Sci 467: 40-54

Frank E, Landgraf R. 2008. The vasopressin system-from antidiuresis to psychopathology. Eur J Pharmacol 583: 226-242.

Gozzi A, Jain A, Giovannelli A, Bertollini C, Crestan V, Schwarz AJ Tsetsenis T, Ragozzino D, Gross CT, Bifone A. 2010. A neural switch for active and passive fear. Neuron 67: 656-666.

Haubensak W, Kunwar PS, Cai H, Ciocchi S, Wall NR, Ponnusamy R, Biag J, Dong HW, Deisseroth K, Callaway EM, et al. 2010. Genetic dissection of an amygdala microcircuit that gates conditioned fear. Nature 468: $270-276$.

Hays WL. 1963. Statistics for psychologists. Holt, Rinehart and Winston, New York.

Herry C, Ciocchi S, Senn V, Demmou L, Müller C, Lüthi A. 2008. Switching on and off fear by distinct neuronal circuits. Nature 454: 600-606.

Huber D, Veinante P, Stoop R. 2005. Vasopressin and oxytocin excite distinct neuronal populations in the central amygdala. Science 308: $245-248$.

Huff NC, Wright-Hardesty KJ, Higgins EA, Matus-Amat P, Rudy JW. 2005. Context pre-exposure obscures amygdala modulation of contextual-fear conditioning. Learn Mem 12: 456-460.

Insel TR. 2010. The challenge of translation in social neuroscience: a review of oxytocin, vasopressin, and affiliative behavior. Neuron 65: 768-779.

Kiernan MJ, Westbrook RF. 1993. Effects of exposure to a to-be-shocked environment upon the rat's freezing response: Evidence for facilitation, latent inhibition and perceptual learning. Q J Exp Psychol B 46: 271-288.

Kirsch P, Esslinger C, Chen Q, Mier D, Lis S, Siddhanti S, Gruppe H, Mattay VS, Gallhofer B, Meyer-Lindenberg A. 2005. Oxytocin modulates neural circuitry for social cognition and fear in humans. J Neurosci 25: 11489-11493.

Knobloch HS, Charlet A, Hoffmann LC, Eliava M, Khrulev S, Cetin AH, Osten P, Schwarz MK, Seeburg PH, Stoop R, et al. 2012. Evoked axonal oxytocin release in the central amygdala attenuates fear response. Neuron 73: $553-566$.

Kremarik P, Freund-Mercier MJ, Stoeckel ME. 1993. Histoautoradiographic detection of oxytocin- and vasopressin-binding sites in the telencephalon of the rat. J Comp Neurol 333: 343-359.

Lahoud N, Maroun M. 2013. Oxytocinergic manipulations in corticolimbic circuit differentially affect fear acquisition and extinction. Psychoneuroendocrinology 38: 2184-2195.

LeDoux J. 2007. The amygdala. Curr Biol 17: R868-R874. 
Lee HJ, Macbeth AH, Pagani JH, Young WS III. 2009. Oxytocin: the great facilitator of life. Prog Neurobiol 88: 127-151.

Lee S, Kim SJ, Kwon OB, Lee JH, Kim JH. 2013. Inhibitory networks of the amygdala for emotional memory. Front Neural Circuits 7: 129.

Likhtik E, Popa D, Apergis-Schoute J, Fidacaro GA, Paré D. 2008. Amygdala intercalated neurons are required for expression of fear extinction. Nature 454: 642-645.

McCarthy MM, McDonald CH, Brooks PJ, Goldman D. 1996. An anxiolytic action of oxytocin is enhanced by estrogen in the mouse. Physiol Behav 60: $1209-1215$

Muller J, Corodimas KP, Fridel Z, LeDoux JE. 1997. Functional inactivation of the lateral and basal nuclei of the amygdala by muscimol infusion prevents fear conditioning to an explicit conditioned stimulus and to contextual stimuli. Behav Neurosci 111: 683-691.

Neumann ID. 2008. Brain oxytocin: a key regulator of emotional and social behaviours in both females and males. J Neuroendocrinol 20: 858-865.

Neumann ID, Landgraf R. 2012. Balance of brain oxytocin and vasopressin: implications for anxiety, depression, and social behaviors. Trends Neurosci 35: 649-659.

Pape HC, Pare D. 2010. Plastic synaptic networks of the amygdala for the acquisition, expression, and extinction of conditioned fear. Physiol Rev 90: $419-463$.

Paxinos G, Watson C. 1997. The rat brain in stereotaxic coordinates, 3rd ed. Academic Press, San Diego.

Penzo MA, Robert V, Li B. 2014. Fear conditioning potentiates synaptic transmission onto long-range projection neurons in the lateral subdivision of central amygdala. J Neurosci 34: 2432-2437.

Petrovic P, Kalisch R, Singer T, Dolan RJ. 2008. Oxytocin attenuates affective evaluations of conditioned faces and amygdala activity. J Neurosci 28: 6607-6615.
Sah P, Westbrook RF, Lüthi A. 2008. Fear conditioning and long-term potentiation in the amygdala: what really is the connection? Ann N Y Acad Sci 1129: 88-95.

Stoop R. 2012. Neuromodulation by oxytocin and vasopressin. Neuron 76: $142-159$.

Terenzi MG, Ingram CD. 2005. Oxytocin-induced excitation of neurones in the rat central and medial amygdaloid nuclei. Neuroscience 134: $345-354$.

Toth I, Neumann ID, Slattery DA. 2012. Central administration of oxytocin receptor ligands affects cued fear extinction in rats and mice in a timepoint-dependent manner. Psychopharmacology (Berl) 223: $149-158$

Viviani D, Charlet A, van den Burg E, Robinet C, Hurni N, Abatis M, Magara F, Stoop R. 2011. Oxytocin selectively gates fear responses through distinct outputs from the central amygdala. Science 333: 104-107.

Wilensky AE, Schafe GE, Kristensen MP, LeDoux JE. 2006. Rethinking the fear circuit: the central nucleus of the amygdala is required for the acquisition, consolidation, and expression of Pavlovian fear conditioning. J Neurosci 26: 12387-12396.

Zoicas I, Slattery DA, Neumann ID. 2014. Brain oxytocin in social fear conditioning and its extinction: involvement of the lateral septum. Neuropsychopharmacology 39: 3027-3035.

Received September 8, 2014; accepted in revised form February 13, 2015. 


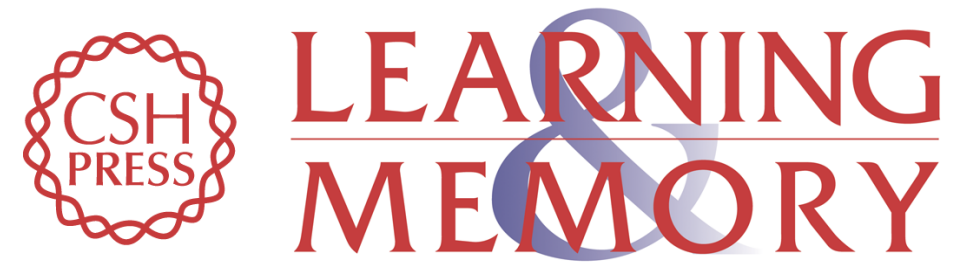

\section{Oxytocin signaling in basolateral and central amygdala nuclei differentially regulates the acquisition, expression, and extinction of context-conditioned fear in rats}

Emma J. Campbell-Smith, Nathan M. Holmes, Nura W. Lingawi, et al.

Learn. Mem. 2015, 22:

Access the most recent version at doi:10.1101/lm.036962.114

References This article cites 42 articles, 9 of which can be accessed free at: http://learnmem.cshlp.org/content/22/5/247.full.html\#ref-list-1

Creative This article is distributed exclusively by Cold Spring Harbor Laboratory Press for the Commons first 12 months after the full-issue publication date (see

License http://learnmem.cshlp.org/site/misc/terms.xhtml). After 12 months, it is available under a Creative Commons License (Attribution-NonCommercial 4.0 International), as described at http://creativecommons.org/licenses/by-nc/4.0/.

Email Alerting Receive free email alerts when new articles cite this article - sign up in the box at the Service top right corner of the article or click here. 